\title{
Trends in suicidal behavior at a general hospital emergency department in southern Brazil
}

\author{
Betina Lejderman, ${ }^{1}$ (D) Aline Parisotto, ${ }^{1}$ Lucas Spanemberg ${ }^{1,2}$ (D)
}

\begin{abstract}
Objective: To assess the prevalence of and factors associated with suicidal behavior in patients seen at the emergency department (ED) of a general hospital in southern Brazil.

Method: Descriptive, observational, cross-sectional study. The records of all patients who had an emergency psychiatric consultation at the ED conducted by the emergency psychiatric consultation service at Hospital São Lucas da Pontifícia Universidade Católica do Rio Grande do Sul in 2016 and 2017 were analyzed and stratified by sex and by age groups (15-29 years, 30-49 years, 50-69 years, and 70 years and older). Suicidal behavior was characterized by factors such as thoughts of death, suicidal thoughts, and suicidal risk. Suicidal behavior was compared by sex and between age groups with chisquare tests. Multivariate analysis of suicidal behavior and gender, age, and specific diagnoses were compared with Poisson regression.

Results: A total of 1,172 records from January 2016 to December 2017 were examined. There were more ED visits by females (63.1\%) than males. Younger patients (15-29 years) had a higher severe risk of suicide than elderly ( $\geq 70$ years) patients $(54.1$ vs. $19 \% ; p<0.01$ ). Indicators of suicide behavior stratified by sex and by age group revealed marked differences between age groups for all variables among female patients. Overall, age group patterns for males were very similar in terms of suicidal behavior variables.

Conclusions: A high prevalence of suicidal behavior was observed in this sample, particularly among young adults and especially associated with female gender and diagnoses of depression and personality disorders.

Keywords: Suicide, suicidal ideation, suicide attempt.
\end{abstract}

\section{Introduction}

According to the World Health Organization (WHO), more than 800,000 people die by suicide each year. ${ }^{1}$ For every suicide, there are many more people who attempt suicide every year and there are indications that for each adult who died of suicide there may have been more than 20 others attempting suicide; significantly, a prior suicide attempt is the single most important risk factor for suicide in the general population. ${ }^{1}$ Suicidal behavior ranges from ideation of killing oneself to forming a plan and obtaining the means to execute the act. Among young people 15-29 years of age, suicide is the second leading cause of death globally, ${ }^{1}$ and the fourth leading cause of death in Brazil. ${ }^{2}$ The global suicide rate is 10.6 per 100,000 people. $^{3}$ The mortality rate from suicide is rising in Brazil, from 5.3 per 100,000 in 2011 to 5.7 per 100,000 in $2015 . .^{2}$ These rates are higher in the southern states of Brazil. In 2016, Rio Grande do Sul, the state with the highest incidence of suicide, had a rate that was double the Brazilian average. ${ }^{4}$ Regardless of the large variability in average suicide rates among

\footnotetext{
${ }^{1}$ Núcleo de Formação em Neurociências, Escola de Medicina, Pontifícia Universidade Católica do Rio Grande do Sul (PUCRS), Porto Alegre, RS, Brazil. ${ }^{2}$ Unidade de Internação Psiquiátrica, Hospital São Lucas, PUCRS, Porto Alegre, RS, Brazil.

Submitted Sep 12 2019, accepted for publication Feb 192020.

Suggested citation: Lejderman B, Parisotto A, Spanemberg L. Trends in suicidal behavior at a general hospital emergency department in southern Brazil. Trends Psychiatry Psychother. 2020;42(4):311-317. http://dx.doi.org/10.1590/2237-6089-2019-0080
} 
Brazilian states, there was a stable or increasing trend in suicide rates from 1997 to 2015 in Brazil. ${ }^{5}$

Suicidal ideation and fatal and nonfatal suicide attempts often begin at age 12-13 and increase during adolescence, ${ }^{6}$ and may establish a pattern of suicidal behavior in young adults. ${ }^{7}$ Suicidal behavior among adolescents and young adults is related to this stage of development, which is characterized by presence of risk factors for suicide such as substance abuse, depression, thrill-seeking, and high-risk behaviors. ${ }^{8}$

The hospital ED is often the gateway to care for unrecognized or untreated cases of mental disorders, including suicide attempts and patients at risk of suicide. 9,10 The risk of suicide or other causes of death following ideation has not been well established. A recent meta-analysis found that suicidal ideation was associated with more than a three-fold increase in the risk of suicide, ${ }^{11}$ but the authors also noted considerable between-study heterogeneity. A significant number of individuals who complete suicide have had contact with the health system in the month prior to death. ${ }^{12}$ The first contact with the health system can offer an excellent opportunity to identify patients at risk and to intervene in potentially fatal cases. In a multicenter study of emergency department patients with elevated suicide risk, a combination of brief interventions administered both during and after the emergency department visit decreased suicidal behavior after discharge. ${ }^{13}$

Despite the importance of and recent increase in suicidal behavior, there is a dearth of studies investigating the prevalence of suicidal behavior in emergency care settings in Brazil. This study aims to describe the prevalence of suicidal thoughts and behaviors in people presenting to the ED at a general hospital in southern Brazil and investigate associations with clinical and sociodemographic variables.

\section{Materials and methods}

\section{Design and sample}

This is a descriptive, observational, cross-sectional study. The records of all patients who had an emergency psychiatric consultation at the Hospital São Lucas emergency department (HSL ED), affiliated with the Pontifícia Universidade Católica do Rio Grande do Sul over a two-year period (January 2016 to December 2017) were analyzed and stratified by sex and by age groups (15-29 years, 30-49 years, 50-69 years, and 70 years and older). Patients under the age of 15 were excluded because they constitute a specific population and there is no specialist pediatric mental health service at the HSL. In total, 1,172 records were analyzed.

\section{Setting}

All patients presenting at the HSL ED are initially screened by a general practitioner. The psychiatric emergency consultation service is called when an urgent need for psychiatric care is identified, such as suicidal behavior, psychomotor agitation, or risk of aggression. The service is staffed by on-call physicians from the HSL residency and fellowship programs in psychiatry. All consultations are entered into the medical record system and the management plan is discussed with the attending physician.

\section{Instrument}

The psychiatric emergency assessment record is routinely used by the HSL psychiatric emergency consultation service as an interview script and on-call log. It is completed by the on-call physician in charge of urgent psychiatric consultation at the time. The record covers 10 items: patient identification and sociodemographic data; reason for evaluation; suicide risk assessment; presence of clinical comorbidities; current or past smoking; use of psychotropic drugs; chemical dependency; history of follow-up by mental health professionals; current medical management; and diagnostic hypothesis. Suicide risk is assessed with the Mini International Neuropsychiatric Interview (MINI), version 5.0.14 The MINI is a brief standardized diagnostic interview used in clinical practice and research in primary care and psychiatry. To assess the risk of suicide, the patient is asked whether, during the last month, they felt they would be better off dead or wanted to be dead; if they meant to harm themselves; if they had ever thought about suicide; if they had thought of a way to attempt suicide; and if they had made a suicide attempt; and also if, at any point in their lives, they had made a suicide attempt. Each affirmative answer is scored. The scores are added to define the patient's risk of suicide as none (0), low (1-5), moderate (6-9), or high $(\geq 10)$. Finally, the patient is asked about family history of completed suicide.

\section{Statistical analysis}

All analyses were performed using the Statistical Package for the Social Sciences (SPSS). For descriptive analysis, continuous variables were presented as mean (standard deviation [SD]), and categorical variables as $\mathrm{n}(\%)$. Between-group differences in continuous variables were analyzed with a t-test for independent samples. Categorical variables were analyzed using the chi-square test. Residuals were adjusted to reveal the differences between categories in each variable. The significance level was set at $p<0.05$. For multivariate analyses of suicidal behavior and gender, age, and specific diagnoses, regressions and prevalence ratios 
were calculated with robust variance. Poisson regression with robust variance was used for these analyses.

\section{Ethical aspects}

This study was approved by the institutional review board at Pontifícia Universidade Católica do Rio Grande do Sul. Data confidentiality was ensured under the terms of a data use agreement. The study protocol is registered in the Brazilian research ethics database under no. CAAE 90002218.0.0000.5336.

\section{Results}

A total of 1,172 records from consultations between January 2016 and December 2017 were examined.
Mean (SD) age was $38.6( \pm 18.1)$ years. There were more ED visits by females than males: $63.1 \%$ of the sample. The most frequent primary complaints in the sample were suicidal ideation (20.0\%) and suicide attempt $(17.7 \%)$. The most common psychiatric diagnosis was unipolar depression (34.7\%), followed by bipolar disorder (16.7\%). Table 1 presents the sociodemographic characteristics for the entire sample and stratified by age ranges.

When the total sample was stratified by age group, statistically significant differences were found in almost all items indicative of suicidal behavior, with the exception of family history of suicide. In general, younger patients (15-29 years) had a higher risk of suicidal behavior than elderly patients. Considering the age groups analyzed, $61.0 \%$ of people aged $15-29$ had suicidal thoughts,

Table 1 - Clinical and sociodemographic characteristics for the whole sample and each age group: HSL ED, 2016 and 2017

\begin{tabular}{|c|c|c|c|c|c|}
\hline Variables & Total sample & $15-29$ years & $30-49$ years & $50-69$ years & $\geq 70$ years \\
\hline Gender female $(n=1,172)$ & $739(63.1)$ & $261(61.0)$ & $285(68.0)$ & $138(56.3)$ & $55(68.8)$ \\
\hline Age $(n=1,172)$ & $38.6 \pm 18.1$ & $20.5 \pm 4.0$ & $38.5 \pm 5.5$ & $57.6 \pm 5.7$ & $78.2 \pm 5.9$ \\
\hline \multicolumn{6}{|l|}{ Marital status $(\mathrm{n}=1,121)$} \\
\hline Single & $494(44.1)$ & $344(83.5)$ & $111(27.5)$ & $32(13.8)$ & $7(9.6)$ \\
\hline Married/cohabitating & $448(40.0)$ & $61(14.8)$ & $226(55.9)$ & $132(56.9)$ & $29(39.7)$ \\
\hline Separated/divorced & $110(9.8)$ & $4(1.0)$ & $54(13.4)$ & $42(18.1)$ & $10(13.7)$ \\
\hline Widowed & $69(6.2)$ & $3(0.7)$ & $13(3.2)$ & $26(11.2)$ & $27(37.0)$ \\
\hline Years of education $(n=983)$ & $11.2 \pm 3.8$ & $10.9 \pm 2.7$ & $11.9 \pm 3.7$ & $11.0 \pm 4.8$ & $9.9 \pm 5.1$ \\
\hline \multicolumn{6}{|l|}{ Occupation ( $\mathrm{n}=1,082)$} \\
\hline Active/employed & $691(63.9)$ & $321(80.5)$ & $259(66.4)$ & $94(42.0)$ & $17(24.6)$ \\
\hline Unemployed & $175(16.2)$ & $68(17.0)$ & $68(17.4)$ & $35(15.6)$ & $4(5.8)$ \\
\hline Retired & $148(13.7)$ & $3(0.8)$ & $22(5.6)$ & $76(33.9)$ & $47(68.1)$ \\
\hline Transient disability & $68(6.3)$ & $7(1.8)$ & $41(10.5)$ & $19(8.5)$ & $1(1.4)$ \\
\hline \multicolumn{6}{|l|}{ Chief complaint ( $n=1,152)$} \\
\hline Suicidal ideation & $230(20.0)$ & $90(21.5)$ & $87(21.0)$ & $48(19.9)$ & $5(6.4)$ \\
\hline Suicide attempt & $204(17.7)$ & $107(25.6)$ & $70(16.9)$ & $23(9.5)$ & $4(5.1)$ \\
\hline Depressive symptoms & $162(14.1)$ & $40(9.6)$ & $67(16.1)$ & $35(14.5)$ & $20(25.6)$ \\
\hline Anxious symptoms & $138(12.0)$ & $44(10.5)$ & $65(15.7)$ & $25(10.4)$ & $4(5.1)$ \\
\hline Psychotic symptoms & $133(11.5)$ & $53(12.7)$ & $40(9.6)$ & $28(11.6)$ & $12(15.4)$ \\
\hline Altered behavior* & $136(11.8)$ & $41(9.8)$ & $27(6.5)$ & $42(17.4)$ & $26(33.3)$ \\
\hline Drug use/misuse & $77(6.7)$ & $23(5.5)$ & $33(8.0)$ & $19(7.9)$ & $2(2.6)$ \\
\hline Manic symptoms & $29(2.5)$ & $6(1.4)$ & $9(2.2)$ & $11(4.6)$ & $3(3.8)$ \\
\hline Other & $43(3.7)$ & $14(3.3)$ & $17(4.1)$ & $10(4.1)$ & $2(2.6)$ \\
\hline \multicolumn{6}{|l|}{ Primary diagnosis $(n=1,103)$} \\
\hline Substance use/misuse & $112(10.2)$ & $41(10.1)$ & $41(10.5)$ & $27(11.5)$ & $3(4.0)$ \\
\hline Psychotic disorder & $105(9.5)$ & $40(9.9)$ & $32(8.2)$ & $24(10.3)$ & $9(12.0)$ \\
\hline Bipolar disorder & $184(16.7)$ & $38(9.4)$ & $70(17.9)$ & $60(25.6)$ & $16(21.3)$ \\
\hline Unipolar depression & $383(34.7)$ & 125 (30.9) & $145(37.2)$ & $87(37.2)$ & $26(34.7)$ \\
\hline Neurotic/anxiety disorder & $157(14.2)$ & $66(16.3)$ & $61(15.6)$ & $24(10.3)$ & $6(8.0)$ \\
\hline Personality disorder & $94(8.5)$ & $62(15.3)$ & $29(7.4)$ & $3(1.3)$ & - \\
\hline Other & $68(6.2)$ & $32(7.9)$ & $12(3.1)$ & $9(3.8)$ & $15(20.0)$ \\
\hline
\end{tabular}

Data presented as $\mathrm{n}(\%)$ or mean \pm standard deviation.

HSL ED = Hospital São Lucas emergency department.

* Includes aggressiveness and psychomotor agitation. 
followed by $51.5 \%$ of people aged $30-49,43.5 \%$ of people aged $50-69$, and $20.3 \%$ of people aged 70 years and over. In the 15-29 age group, 35.2\% had attempted suicide in the previous month, followed by $29.4 \%$ of people aged $30-49,17.2 \%$ of people aged $50-69$, and $13.9 \%$ of people aged 70 years and over. Differences in suicidal behavior by age group are described in Table 2 .

Analysis of differences in indicators of suicide behavior stratified by sex and by age group revealed marked differences between age groups for all variables among female patients. For severe suicide risk, the 1529 years age group were at higher risk of suicide than the 50-69 years and 70 years and over age groups ( 60.5 vs. $38.2 \%$ vs. $13.0 \%, p<0.001)$. The lifetime suicide attempt rate was $44.7 \%$ among females aged 15-29 years, $41.8 \%$ among females aged $30-49$, 30.4\% among females aged 50-69, and 18.5\% among females aged 70 years and over ( $p<0.001$ for $15-29$ years vs. 50-69 and 70 years and over). The age group patterns for males were overall very similar in variables of suicidal behavior. The lifetime suicide attempt rate was $28.9 \%$ among males aged $15-29$ years, $28.1 \%$ among males aged 30-49, 23.5\% among males aged 50-69, and $25.0 \%$ among males aged 70 years and over. The results stratified by sex are shown in Table 3.

Univariate analyses were also conducted of associations between variables related to suicide risk and International Classification of Diseases, 10th revision (ICD-10). Major depressive disorder and personality disorders were associated with all variables related to suicidal behavior, with the exception of family history of suicide.

Table 2 - Differences in suicidal behavior by age group: HSL ED, 2016 and 2017

\begin{tabular}{|c|c|c|c|c|c|c|}
\hline & Total sample & $15-29$ years & $30-49$ years & $50-69$ years & $\geq 70$ years & $\mathbf{p}$ \\
\hline Thoughts of death & $634(55.7)$ & $261(62.6)^{3.6}$ & $235(58.3)$ & $111(46.4)^{-3.2}$ & $27(34.2)^{-4.0}$ & $<0.01$ \\
\hline Want to hurt yourself & $530(46.5)$ & $241(57.7)^{5.7}$ & $185(45.9)$ & $87(36.4)^{-3.5}$ & $17(21.5)^{-4.6}$ & $<0.01$ \\
\hline Suicidal thoughts & $582(51.1)$ & $255(61.0)^{5.1}$ & $207(51.5)$ & $104(43.5)^{-2.7}$ & $16(20.3)^{-5.7}$ & $<0.01$ \\
\hline Thinking about a way to kill yourself & $474(41.8)$ & $208(49.9)^{4.2}$ & $175(43.8)$ & $79(33.1)^{-3.1}$ & $12(15.2)^{-5.0}$ & $<0.01$ \\
\hline Suicide attempt & 317 (27.9) & $147(35.2)^{4.2}$ & $118(29.4)$ & $41(17.2)^{-4.2}$ & $11(13.9)^{-2.9}$ & $<0.01$ \\
\hline Lifetime suicide attempt & $389(34.6)$ & $160(38.6)^{2.2}$ & $148(37.4)$ & $65(27.4)^{-2.6}$ & $16(20.5)^{-2.7}$ & $<0.01$ \\
\hline \multicolumn{7}{|l|}{ Risk of suicide } \\
\hline None & $414(36.4)$ & $119(28.5)^{-4.2}$ & $135(33.7)$ & $113(47.3)^{3.9}$ & $47(59.5)^{4.4}$ & $<0.01$ \\
\hline Slight risk & $138(12.1)$ & $41(9.8)$ & $57(14.2)$ & $25(10.5)$ & $15(19.0)$ & \\
\hline Moderate risk & $76(6.7)$ & $32(7.7)$ & $27(6.7)$ & $15(6.3)$ & $2(2.5)$ & \\
\hline Severe risk & $509(44.8)$ & $226(54.1)^{4.8}$ & $182(45.4)$ & $86(36.0)^{-3.1}$ & $15(19.0)^{-4.8}$ & \\
\hline Family history of suicide & $96(9.4)$ & $42(11.4)$ & $31(8.4)$ & $19(8.7)$ & $4(5.9)$ & 0.34 \\
\hline
\end{tabular}

Data presented as $\mathrm{n}(\%)$.

HSL ED = Hospital São Lucas, emergency department.

Superscript values denote residuals adjusted for post-hoc differences.

Bold type denotes $p<0.05$, analyzed by the chi-square test.

Table 3 - Differences in suicide behavior between age groups, stratified by sex: HSL ED, 2016 and 2017

\begin{tabular}{|c|c|c|c|c|c|c|c|c|c|c|c|c|}
\hline & \multicolumn{6}{|c|}{ Females } & \multicolumn{6}{|c|}{ Males } \\
\hline & total $\mathbf{n}$ & $\begin{array}{l}15-29 \\
\text { years }\end{array}$ & $\begin{array}{l}30-49 \\
\text { years }\end{array}$ & $\begin{array}{l}50-69 \\
\text { years }\end{array}$ & $\begin{array}{l}\geq 70 \\
\text { years }\end{array}$ & $\mathbf{p}$ & total $\mathbf{n}$ & $\begin{array}{l}15-29 \\
\text { years }\end{array}$ & $\begin{array}{l}30-49 \\
\text { years }\end{array}$ & $\begin{array}{l}50-69 \\
\text { years }\end{array}$ & $\begin{array}{l}\geq 70 \\
\text { years }\end{array}$ & $\mathbf{p}$ \\
\hline Thoughts of death & $438(60.7)$ & $183(70.9)^{4.2}$ & $170(62.0)$ & $67(49.3)^{-3.0}$ & $18(33.3)^{-4.3}$ & $<0.01$ & $196(47.1)$ & $78(49.1)$ & $65(50.4)$ & $44(42.7)$ & $9(36.0)$ & 0.42 \\
\hline Want to hurt yourself & $366(50.7)$ & $168(65.1)^{5.8}$ & $135(49.3)$ & $53(39.0)^{-3.0}$ & $10(18.5)^{-4.9}$ & $<0.01$ & $164(39.3)$ & $73(45.6)$ & $50(38.8)$ & $34(33.0)$ & $7(28.0)$ & 0.13 \\
\hline Suicidal thoughts & $400(55.4)$ & $179(69.4)^{5.6}$ & $150(54.7)$ & $63(46.3)^{-2.4}$ & $8(14.8)^{-6.2}$ & $<0.01$ & $182(43.8)$ & $76(47.5)$ & $57(44.5)$ & $41(39.8)$ & $8(32.0)$ & 0.39 \\
\hline $\begin{array}{l}\text { Thinking about a way to } \\
\text { kill yourself }\end{array}$ & $323(44.8)$ & $141(54.9)^{4.0}$ & $130(47.4)$ & $46(33.8)^{-2.9}$ & $6(11.1)^{-5.2}$ & $<0.01$ & $151(36.5)$ & $67(41.9)$ & $45(35.7)$ & $33(32.0)$ & $6(24.0)$ & 0.20 \\
\hline Suicide attempt & $214(29.8)$ & $97(37.7)^{3.5}$ & $88(32.4)$ & $24(17.6)^{-3.4}$ & $5(9.3)^{-3.4}$ & $<0.01$ & $103(24.6)$ & $50(31.1)$ & $30(23.3)$ & $17(16.5)$ & $6(24.0)$ & 0.06 \\
\hline Lifetime suicide attempt & 277 (38.9) & $114(44.7)^{2.4}$ & $112(41.8)$ & $41(30.4)^{-2.3}$ & $10(18.5)^{-3.2}$ & $<0.01$ & $112(27.1)$ & $46(28.9)$ & $36(28.1)$ & $24(23.5)$ & $6(25.0)$ & 0.79 \\
\hline \multicolumn{13}{|l|}{ Risk of suicide } \\
\hline None & $225(31.2)$ & $51(19.8)^{-4.9}$ & $83(30.3)$ & $60(44.1)^{3.6}$ & $31(57.4)^{4.3 .}$ & $<0.01$ & $189(45.5)$ & $68(42.5)$ & $52(40.9)$ & $53(51.5)$ & $16(64.0)$ & 0.19 \\
\hline Slight risk & $97(13.4)$ & $28(10.9)$ & $40(14.6)$ & $15(11.0)$ & $14(25.9)^{2.8}$ & & $41(9.9)$ & $13(8.1)$ & $17(13.4)$ & $10(9.7)$ & $1(4.0)$ & \\
\hline Moderate risk & $49(6.8)$ & $23(8.9)$ & $15(5.5)$ & $9(6.6)$ & $2(3.7)$ & & $27(6.5)$ & $9(5.6)$ & $12(9.4)$ & $6(5.8)$ & - & \\
\hline Severe risk & $351(48.6)$ & $156(60.5)^{4.8}$ & $136(49.6)$ & $52(38.2)^{-2.7}$ & $7(13.0)^{-5.4}$ & & $158(38.1)$ & $70(43.8)$ & $46(36.2)$ & $34(33.0)$ & $8(32.0)$ & \\
\hline Family history of suicide & $61(9.5)$ & $29(13.0)^{2.2}$ & $20(8.0)$ & $8(6.4)$ & $4(8.9)$ & 0.15 & $35(9.2)$ & $13(9.0)$ & $11(9.2)$ & $11(11.8)$ & - & 0.38 \\
\hline
\end{tabular}

Data presented as n (\%).

HSL ED = Hospital São Lucas emergency department.

Bold type denotes $p<0.05$, analyzed by the chi-square test. 
Table 4 - Multivariate analysis of associations between variables associated with suicidal behavior and gender, age, and specific diagnoses (unipolar depression and personality disorder): HSL ED, 2016 and 2017

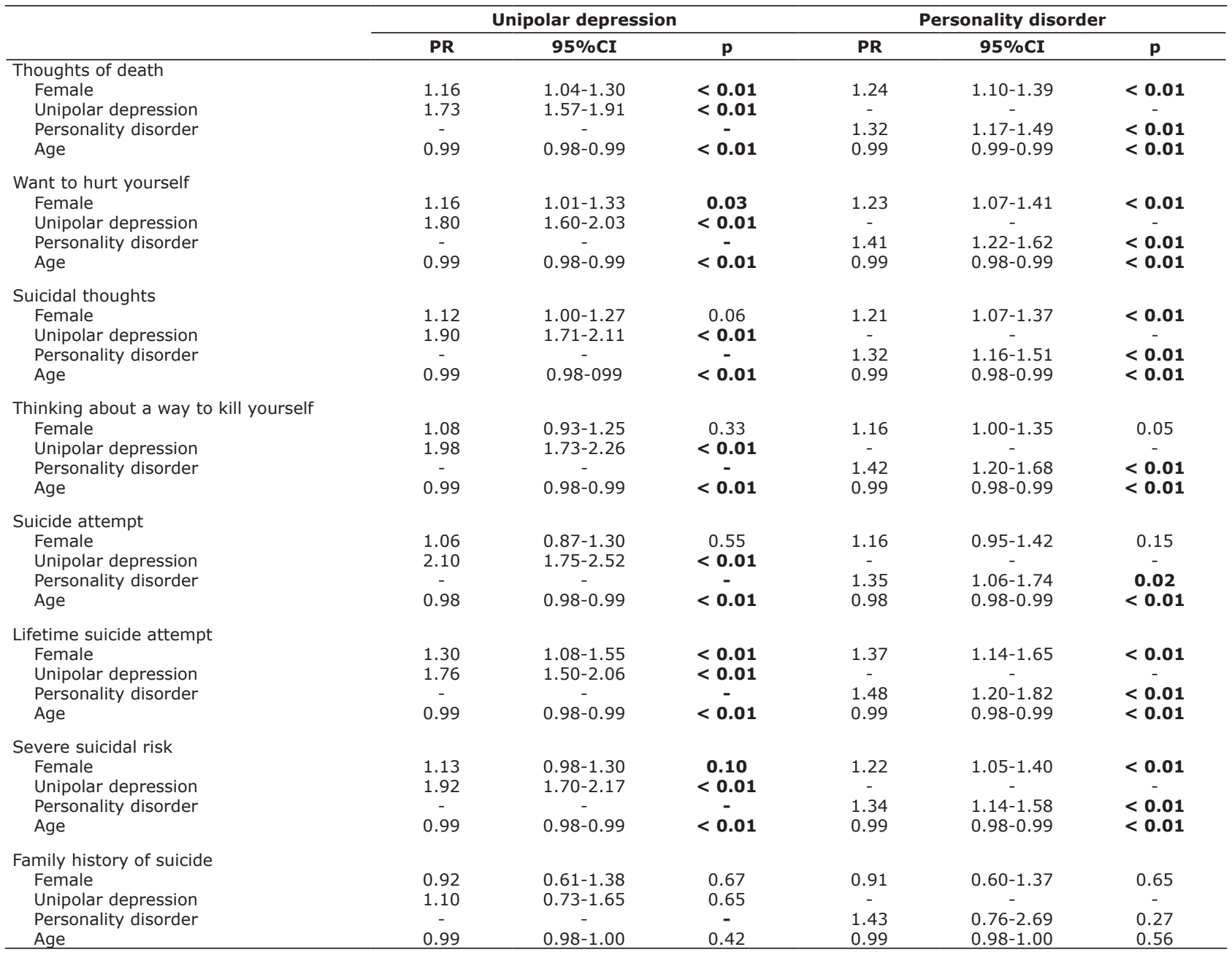

$95 \%$ CI = 95\% confidence interval; HSL ED = Hospital São Lucas emergency department; PR = prevalence ratio.

Bold type denotes $\mathrm{p}<0.05$; analyzed by Poisson regression.

Multivariate analysis adjusted for gender, unipolar depression, and age indicated that female gender, young age, and a diagnosis of depression are risk factors for suicidal behavior. A significant association with female gender was found in half of the variables associated with suicidal behavior: thoughts of death, wanting to hurt oneself, lifetime suicide attempts, and severe suicide risk. There was no association between family history of suicide and suicidal behavior. Multivariate analysis adjusted for gender, personality disorder, and age revealed that female gender, young age, and diagnosis of personality disorder were risk factors for almost all variables related to suicidal behavior, except for thinking about a way to kill oneself and current suicide attempt, which were not associated with gender. Once more, there was no association between family history of suicide and suicidal behavior (Table 4).

\section{Discussion}

The objective of this study was to analyze clinical and sociodemographic differences associated with suicidal behavior in patients seen at the ED by an emergency psychiatric consultation service at a general hospital. The results showed a high prevalence of suicidal behavior, most strongly associated with younger age, female gender, and diagnoses of depression and personality disorders. Approximately half of the subset aged 15-29 had suicidal thoughts and one-third of these young people had attempted suicide at least once before. Studies conducted in emergency departments in Brazil confirm the predominance of suicide attempts in the young population, especially among women. ${ }^{15-17}$ Since one of the main demands of psychiatric emergency consultation services is suicidal behavior, the fact that there are high 
rates of suicidal ideation and suicide attempt in the sample is unsurprising. We nevertheless highlight the finding that one third of the youngest group of patients had attempted suicide at least once before. In a previous study investigating emergency psychiatric care at our facility, the number one specific reason for psychiatric care among children and adolescents was suicide attempts. ${ }^{18}$

In our study, suicidal behavior was mainly associated with young age. The highest prevalence of severe suicide risk was identified in the 15-29 years age group. This age group also had higher prevalence rates of suicide attempts both in the last month and lifelong. A study conducted in emergency departments in the United States also found higher incidence of suicide attempts among women and individuals aged 15-19.19

Between 2011 and 2016, 69.0\% of reported suicide attempts in Brazil were by women and the suicide attempts by women predominate in adolescence (10-19 years) and young adulthood (20-39 years). ${ }^{20}$ However, the risk of suicide is approximately four times greater in males. There is a discrepancy between the number of suicides and attempted suicides, with one possible explanation being the preferred methods of each gender: despite making more suicide attempts, women use less effective methods than men. ${ }^{21}$ This difference in behavior between the genders may explain the higher prevalence of women presenting to emergency departments, $15,16,22$ coinciding with our sample - in which female patients presented with a higher prevalence of suicidal behavior.

Studies have shown an association between mental illness and suicide. ${ }^{23,24}$ In our sample, the main mental health diagnosis was unipolar depression, which is one of the leading risk factors for suicide. Depressed patients are 20 times more likely to commit suicide than the general population. ${ }^{25}$ Depression is increasing among adolescents and young adults, especially among females. ${ }^{26}$ A recent study demonstrated increases in suicide rates since 2006. ${ }^{27}$ Self-inflicted injuries in adolescence may be indicative of the development of borderline personality disorder. ${ }^{28}$ A survey of young people in the United States (aged 10 to 24) between 2001 and 2015 showed an increase in the rate of females presenting to emergency departments with selfinflicted injuries from 2008 to $2015 .^{29}$ In our sample, a diagnosis of a personality disorder was a risk factor for suicidal behavior. Thus, it is important to detect mental disorders and investigate suicidal behavior in all psychiatric disorders, especially when depression and personality disorder are in the differential diagnosis.

Many patients who seek care for nonpsychiatric complaints at emergency departments have undiagnosed mental illness. ${ }^{30}$ One study has shown that although suicidal ideation is frequent in adolescents seen in emergency departments, it goes unnoticed by physicians and patients are not referred to mental health services. ${ }^{31}$ Screening youth for suicidal behavior is an important way of preventing suicide. ${ }^{32}$ Use of standard screening tools in primary care increases detection of suicidal ideation, enabling referral to mental health services before a serious or fatal suicide attempt occurs. ${ }^{33}$ Effective intervention for suicide prevention includes involvement of family members and caregivers to provide young people with the necessary support and ensure commitment to followup after ED discharge. ${ }^{34}$ It is equally important to continue investigating suicidal behavior during such follow-up. ${ }^{35}$

This study has some limitations. The psychiatric emergency assessment record is completed by an oncall physician, and its items focus on delivery of urgent care; other information that is potentially useful from a research standpoint is not collected, and some records are incomplete. Since data collection occurred in a naturalistic environment, information such as the diagnostic hypothesis was obtained through a clinical interview (i.e., without the aid of psychometric instruments) and at a single point in time, and is thus susceptible to recall and information bias. Furthermore, data collection took place in a nonpsychiatric department of a general teaching hospital that mostly serves patients with private health insurance and the findings are not therefore generalizable.

The hospital does not have a specialized pediatric psychiatry service and all potential psychiatric patients (including children and adolescents) are seen by professionals trained in general psychiatry. Furthermore, as a matter of course, the population sample was limited to patients who sought care at HSL.

\section{Conclusions}

We found a high prevalence of suicidal behavior in this sample of patients seeking emergency psychiatric consultation at a general hospital, particularly among young women. Suicidality was associated mainly with young age and with diagnoses of depression and personality disorders. These findings highlight the need for robust assessment in general emergency departments, training of emergency department staff (including in the use of standardized tools to screen for suicidal behavior), and referral to specialized mental health services when needed.

\section{Disclosure}

No conflicts of interest declared concerning the publication of this article. 


\section{References}

1. World Health Organization (WHO). Preventing suicide: a global imperative. Geneva: WHO; 2014.

2. Brasil. Ministério da Saúde. Setembro Amarelo: Ministério da Saúde lança agenda estratégica de prevenção do suicídio [Internet]. 2017. http://portalarquivos.saude.gov.br/images/ pdf/2017/setembro/21/Coletiva-suicidio-21-09.pdf.

3. World Health Organization. Suicide estimates [Internet]. 2016. https://www.who.int/mental_health/prevention/suicide/ estimates/en/.https://www.who.int/mental_health/prevention/ suicide/estimates/en/

4. Centro Estadual em Vigilância em Saúde (CEVS). Boletim de Vigilância Epidemiológica de Suicídio e Tentativa de Suicídio [Internet]. 2018. https://www.cevs.rs.gov.br/ upload/arquivos/201809/05162957-boletim-de-vigilanciaepidemiologica-de-suicidio-n1-2018.pdf

5. Rodrigues CD, de Souza DS, Rodrigues HM, Konstantyner TC. Trends in suicide rates in Brazil from 1997 to 2015. Braz J Psychiatry. 2019;41:380-8.

6. Nock MK, Green JG, Hwang I, McLaughlin KA, Sampson NA, Zaslavsky AM, et al. Prevalence, correlates, and treatment of lifetime suicidal behavior among adolescents: results from the National Comorbidity Survey Replication Adolescent Supplement. JAMA Psychiatry. 2013;70:300-10.

7. Borges G, Angst J, Nock MK, Ruscio AM, Kessler RC. Risk factors for the incidence and persistence of suicide-related outcomes: a 10-year follow-up study using the National Comorbidity Surveys. J Affective Disord. 2008;105:25-33.

8. Horwitz AG, Czyz EK, King CA. Predicting future suicide attempts among adolescent and emerging adult psychiatric emergency patients. J Clin Child Adolesc Psychol. 2015;44:751-61.

9. Mahajan P, Alpern ER, Grupp-Phelan J, Chamberlain J, Dong L, Holubkov R, et al. Epidemiology of psychiatric-related visits to emergency departments in a multicenter collaborative research pediatric network. Pediatr Emerg Care. 2009;25:715-20.

10. American Academy of Pediatrics, Committee on Pediatric Emergency Medicine; American College of Emergency Physicians and Pediatric Emergency Medicine Committee; Dolan MA, Mace SE. Pediatric mental health emergencies in the emergency medical services system. Pediatrics. 2006;118:1764-7.

11. McHugh CM, Corderoy A, Ryan CJ, Hickie IB, Large MM. Association between suicidal ideation and suicide: meta-analyses of odds ratios, sensitivity, specificity and positive predictive value. BJPsych Open. 2019;5:e18.

12. Pearson A, Saini P, Da Cruz D, Miles C, While D, Swinson N, et al. Primary care contact prior to suicide in individuals with mental illness. Br J Gen Pract. 2009;59:825-32.

13. Miller IW, Camargo CA, Arias SA, Sullivan AF, Allen $\mathrm{MH}$, Goldstein $A B$, et al. Suicide prevention in an emergency department population: the ED-SAFE study. JAMA Psychiatry. 2017;74:56370.

14. Amorim P. Mini International Neuropsychiatric Interview (MINI): validação de entrevista breve para diagnóstico de transtornos mentais. Rev Bras Psiquiatr. 2000;22:106-15.

15. Santos SA, Lovisi G, Legay $L$, Abelha L. Prevalência de transtornos mentais nas tentativas de suicídio em um hospital de emergência no Rio de Janeiro. Cad. Saúde Pública. 2009;25:2064-74.

16. Werneck GL, Hasselmann MH, Phebo LB, Vieira DE, Gomes VLO. Tentativas de suicídio em um hospital geral no Rio de Janeiro. Cad. Saúde Pública. 2006;22:2201-6.

17. Sá NNB, Oliveira MGC, Mascarenhas MDM, Yokota RTC, Silva MMA, Malta DC. Atendimentos de emergência por tentativas de suicídio. Rev Med Minas Gerais.2010;20:145-152.

18. Tonezer J, Muller T, Rocha GP, Recondo R, Nogueira EL, Spanemberg L. Clinical profile and sex differences in Brazilian children and adolescents receiving psychiatric services in the emergency department. Pediatr Emergency Care. 2015 Jun 27. doi: 10.1097/PEC.0000000000000505. Online ahead of print.

19. Canner J, Giuliano K, Selvarajah S, Hammond E, Schneider E. Emergency department visits for attempted suicide and self harm in the USA: 2006-2013. Epidemiol Psychiatr Sci. 2018;27:94102.

20. Brasil. Secretaria de Vigilância em Saúde - Ministério da Saúde. Perfil epidemiológico das tentativas de óbitos por suicídio no Brasil e a rede de atenção à saúde. Boletim Epidemiológico, vol. 48. nº 30. In: Suicídio. Saber, agir e prevenir. [Internet]. Secretaria de Vigilância em Saúde (SVS). (2017b); 2017. http://www.crianca. mppr.mp.br/arquivos/File/publi/ms/perfil_epidemiologico_ suicidio ms2017.pdf.

21. Baptista MN, Cardoso HF, Carneiro AM, Gomes JO. Análise epidemiológica do suicídio em duas regiões do estado de São Paulo entre 2004 e 2008. Psicol Pesq. 2012;6:2-12.

22. Alves VM, Francisco LC, de Melo AR, Novaes CR, Belo FM, Nardi AE. Trends in suicide attempts at an emergency department. Rev Bras Psiquiatr. 2017;39:55-61.

23. Röcker $S$, Bachmann S. Suicidality in mental illness-prevention and therapy. Ther Umsch. 2015;72:611-7.

24. Cho SE, Na KS, Cho SJ, Im JS, Kang SG. Geographical and temporal variations in the prevalence of mental disorders in suicide: systematic review and meta-analysis. J. Affect. Disord. 2016;190:704-13.

25. Lépine J-P, Briley M. The increasing burden of depression. Neuropsych Dis Treat. 2011;7(Suppl 1):3.

26. Mojtabai R, Olfson M, Han B. National trends in the prevalence and treatment of depression in adolescents and young adults. Pediatrics. 2016;138:e20161878.

27. Curtin SC, Warner $M$, Hedegaard $H$. Increase in suicide in the United States, 1999-2014. NCHS Data Brief. 2016;Apr:1-8.

28. Crowell SE, Beauchaine TP, McCauley E, Smith CJ, Stevens AL, Sylvers P. Psychological, autonomic, and serotonergic correlates of parasuicide among adolescent girls. Dev Psychopathol. 2005; 17:1105-27.

29. Mercado MC, Holland K, Leemis RW, Stone DM, Wang J. Trends in emergency department visits for nonfatal self-inflicted injuries among youth aged 10 to 24 years in the United States, 20012015. Jama. 2017;318:1931-3.

30. La Vonne AD, Zun LS, Burke T. Undiagnosed mental illness in the emergency department. J Emerg Med. 2012;43:876-82.

31. Kemball RS, Gasgarth R, Johnson B, Patil M, Houry D. Unrecognized suicidal ideation in ED patients: are we missing an opportunity? Am J Emerg Med. 2008;26:701-5.

32. Horowitz LM, Bridge JA, Boudreaux ED. Screening youth for suicide risk in medical settings: time to ask questions. Am J Prev Med. 2014;47:S170-S5.

33. Wintersteen MB. Standardized screening for suicidal adolescents in primary care. Pediatrics. 2010; 125:938-44.

34. Babeva K, Hughes JL, Asarnow J. Emergency department screening for suicide and mental health risk. Curr Psychiatry Rep. 2016;18:100.

35. López-Goñi JJ, Goñi-Sarriés A, Azcárate-Jiménez L, SabaterMaestro P. Suicidal behaviour recurrence in psychiatric emergency departments of patients without a prior suicide attempt, index and reattempters: a prospective study. Rev Psiquiatr Salud Ment. 2018;S1888-9891(18)30074-0. Online ahead of print.

\section{Correspondence:}

Betina Lejderman

Av. Ipiranga, 6681

90619-900 - Porto Alegre, RS - Brazil

Tel.: +5551997016646

E-mail: betinalejderman@gmail.com 